\title{
Symptomatic Bradyarrhythmias in the Adult: Natural History Following Ventricular Pacemaker Implantation
}

\author{
ARTHUR B. SIMON and NANCY JANZ \\ From the Departments of Internal Medicine, Division of Cardiology and Nursing Services of the University of \\ Michigan Medical Center, Ann Arbor, Michigan
}

\begin{abstract}
SIMON, A.B., AND JANZ, N.: Symptomatic bradyarrhythmias in the adult: natural history following ventricular pacemaker implantation. The preimplantation arrhythmias, coexistent medical conditions, the causes of death, and survival course are described for 399 patients who received their initial ventricular pacemaker implantation for a bradyarrhythmia (AV block, sinus node disease, and hypersensitive carotid sinus syndrome) at the University of Michigan from 1961 to 1979. Factors which correlated with a poor survival are elucidated. Survival for those with sinus node disease was virtually identical to those with AV block, with only $63 \%$ surviving over five years. Advanced age and congestive heart failure prior to implantation, and underlying ischemic or hypertensive heart disease portended a poorer survival in both groups. Patients with hypersensitive carotid sinus syndrome had a distinctly better prognosis-no deaths occurred until the eighth year after pacing. Patients with no underlying heart disease and those with valvular disease did remarkably better than those with an ischernic or myopathic etiology. Apparent progression or complications of the underlying heart disease was the major cause of mortality. Sudden death, congestive heart failure, myocardial infarction, and major arrhythmias were the causes of death in $48 \%$ of those who died. Implications of improved pacing modalities on late complications and death are discussed. (PACE, Vol. 5, May-June, 1982)
\end{abstract}

bradyarrhythmias, ventricular pacemaker

For nearly two decades permanent pacemakers have been the treatment of choice for high grade atrioventricular block. Sinus node disease and other bradyarrhythmias have been recognized with increasing frequency, so that now in the United States, patients with these latter disorders constitute $30-50 \%$ of all patients receiving their initial pacemaker implantation. Although initially pacemaker implantation was considered an investigative procedure performed only at a few university centers, these implants are now performed with acceptable complication rates by adequately trained personnel at many community hospitals worldwide.

Within the last few years improvements in power sources and leads, as well as micro-

Address for reprints: Arthur B. Simon, M.D., 3200 Burnet Avenue, Cincinnati, Ohio 45229

Received July 15, 1981; revision received August 18, 1981; accepted August 18, 1981. processor technology, have resulted in smaller, longer lasting, and improved pacing devices. This has enabled the clinician to normalize cardiac function more completely through retention of atrioventricular synchrony and to make periodic adjustments in pacing system performance which might reduce late morbidity and mortality. In addition, as a result of these more physiologic pacing modes, the longevity and quality of life of these patients with bradyarrhythmias may be substantially improved over that achieved with ventricular pacing alone. It seems germane, therefore, to summarize the current status of patients with symptomatic bradyarrhythmias treated over the previous two decades with ventricular pacing in order to 1) describe survivorship and causes of late mortality; 2) to identify those conditions in the patient population which correlate with a poor prognosis; 3) to enumerate the causes of late morbidity and mortality; and 4) to discuss how improvements in pacing system technology 
might improve survival. Data of this type would appear to be necessary in order to measure accurately any effects future technology may have on this patient population.

\section{Methods}

\section{Patient Selection}

The records of all adult patients who received their initial permanent pacemaker implantation at the University of Michigan were reviewed. These patients have been the subjects of several previous reports from this institution on indications, techniques, and complications of implantation and natural history of patients with permanent pacemakers. ${ }^{1-10}$ This report continues follow-up observations to December 31, 1979 for all patients receiving their initial pacemaker implant prior to April 1, 1979. Data on past history, the indication for pacemaker placement, subsequent clinical course, and complications were summarized and the data transferred to computer tape. Data were analyzed using standard statistical methods. The MIDAS, ${ }^{11}$ and IGSAS ${ }^{12}$ data analysis systems were utilized. Differences between groups were analyzed by chi squared method, and survival was determined by the life table method. ${ }^{13,14}$ The Breslow's generalized Kruskal-Wallis Test was utilized to determine if the survival distribution differed across strata for any single preimplantation variable..$^{15}$

The etiology of underlying heart disease for patients in this series was based on the available clinical data at the time of diagnosis of the bradyarrhythmia. Electrocardiographic criteria alone were used for classification of subgroups; electrophysiologic studies were employed in only a few patients after 1972 . Criteria for admission into each etiologic category were similar to that previously described (e.g., whether the apparent underlying heart disease was arteriosclerotic, hypertensive, rheumatic, congenital, valvular, or due to a cardiomyopathy) ${ }^{9}$ Patients were considered to have "idiopathic conduction system disease" if there was no underlying valvular, myocardial, arteriosclerotic or hypertensive disease, and heart size was normal or nearly so, without congestive heart failure at initial implantation.

\section{Determination of the Cause of Death}

Details concerning the circumstances of death were obtained by interview with family members, the patient's physician, and other informed witnesses. All available medical records including autopsy data were reviewed whenever possible. Mortality data on deaths after 1972 were collected within six weeks of death, while data on those who died prior to 1972 were obtained, in part, retrospectively, Sudden death was defined as death within one hour after the onset of symptoms. Death due to myocardial infarction was based on a definite history of sustained typical ischemic precordial chest pain and other symptoms which terminated in death and whenever possible, supplemented by ECG, enzyme, or autopsy confirmation. Congestive heart failure was diagnosed by the criteria of McKee ${ }^{16}$ For the purposes of this report, only adults (over age 21) were included whose indication for pacing was a bradyarrhythmia. Experience with children with permanent pacemaker implants from this institution will be reported upon elsewhere. ${ }^{17} \mathrm{~A}$ few adults paced for ventricular tachyarrhythmias in the mode of "overdrive" suppression, and one patient paced with an antitachycardia device are not included in this report. Since 1965, patients were followed in a pacemaker clinic no less frequently than every six months. For the patients who were followed outside the institution, telephone or written reports on cardiovascular status were obtained annually. During the follow-up interval patients were paced with General Electric, ${ }^{*}$ Medtronic, ${ }^{* *}$ Cordis, $\dagger$ and CPI‡ pacing systems.

\section{Results}

\section{Description of the Population}

The 399 adult patients included in this report were divided into three categories according to their specific bradyarrhythmia. The indication

\footnotetext{
${ }^{\star}$ General Electric, Milwaukee, Wisconsin, U.S.A.

${ }^{* *}$ Medtronic, Inc., Minneapolis, Minnesota, U.S.A.

†Cordis Corp., Miami, Florida, U.S.A.

$\ddagger$ Cardiac Pacemakers, Inc., St. Paul, Minnesota, U.S.A.
} 
for pacing and age distribution for the patients is shown on Figure 1. There were 312 patients with atrioventricular block (AVB), 75 patients with sinus node disorders (SND), and 12 patients with hypersensitive carotid sinus syndrome (HCSS). In this population, $44 \%$ had no apparent heart disease at the time of their initial implant, $30 \%$ had ischemic heart disease. Valvular heart disease was present in $18 \%$, and congenital heart disease in $2 \%$ (Table I). One patient had a bullet wound to the heart resulting in AV block, and one patient had leukemia and intermittent sepsis, either one of which may have been responsible for AV block. Approximately onethird of the patients were under the age of 65 , one-third were $65-74$, and one-third over age 75 at the time of initial pacemaker implantation (Table I). Sixty-two percent were male. There were no significant differences in age distribution between the two major bradyarrhythmia categories-AV block and sinus node dis- orders-but the group with hypersensitive carotid sinus syndrome was younger. The sinus node group had a larger percentage with ischemic heart disease and less with aortic valve disease. Hypertension, congestive heart failure, cerebrovascular disease, diabetes, chronic renal disease, cancer, and obstructive lung disease were common in the study sample (Table II). There were no significant differences in the prevalence of the specified associated illnesses in the three bradyarrhythmia categories. The AV block group had a higher prevalence of cardiomegaly, possibly corresponding to a higher prevalence of hypertension. Diabetes mellitus was very prevalent in all categories and far more common than in age matched controls, as has been previously reported. ${ }^{8-10}$ Within the sinus node disease group, $13(17 \%)$ had sinus bradycardia alone, $34(45 \%)$ had sinus bradycardia in combination with symptomatic sinoatrial arrest, and $28(37 \%)$ had sinus bradycardia and

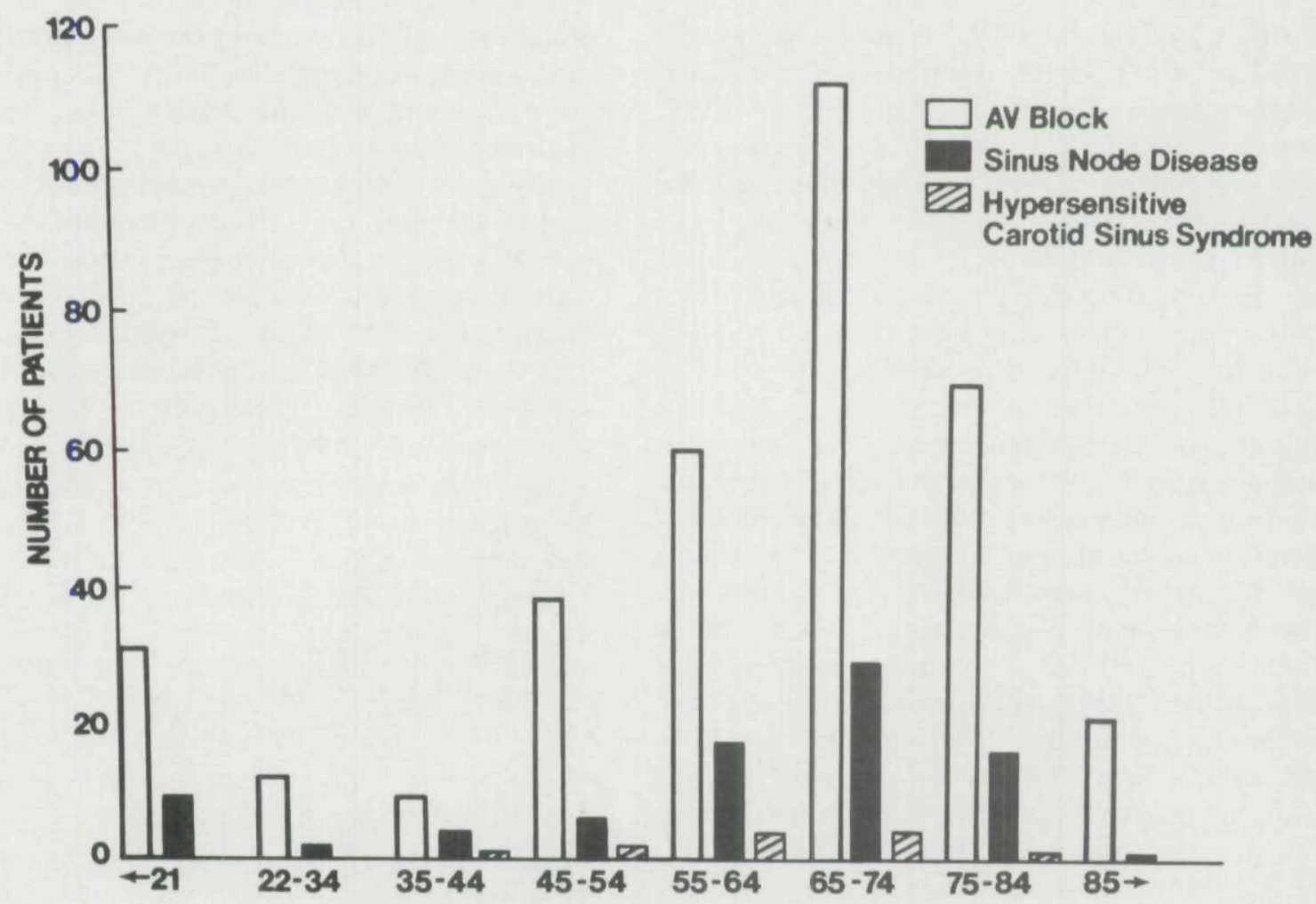

Figure 1. Age at initial pacemaker implantation. 
Table I.

The Major Descriptive Variables in the Patients Studied

\begin{tabular}{|c|c|c|c|c|c|c|c|c|}
\hline \multirow[b]{2}{*}{ Age Distribution } & \multicolumn{2}{|c|}{$\begin{array}{c}\text { AV Block } \\
n=312\end{array}$} & \multicolumn{2}{|c|}{$\begin{array}{c}\text { Sinus Node } \\
\text { Disorders } \\
n=75\end{array}$} & \multicolumn{2}{|c|}{$\begin{array}{l}\text { Hypertensive } \\
\text { Carotid Sinus } \\
\qquad n=12\end{array}$} & \multicolumn{2}{|c|}{$\begin{array}{c}\text { Total } \\
n=399\end{array}$} \\
\hline & No. & $\% *$ & No. & $\% *$ & No. & $\% *$ & No. & $\% *$ \\
\hline 65 & 110 & 35 & 29 & 39 & 7 & 58 & 146 & 37 \\
\hline $65-74$ & 112 & 36 & 29 & 39 & 4 & 33 & 145 & 36 \\
\hline \multirow[t]{2}{*}{74} & 90 & 29 & 17 & 23 & 1 & 8 & 108 & 27 \\
\hline & \multicolumn{2}{|c|}{ mean $=67$} & \multicolumn{2}{|c|}{ mean $=65$} & \multicolumn{2}{|c|}{ mean $=63$} & & \\
\hline \multicolumn{9}{|l|}{ Sex } \\
\hline Male & 201 & 64 & 38 & 51 & 8 & 67 & 247 & 62 \\
\hline Female & 111 & 36 & 37 & 49 & 4 & 33 & 152 & 38 \\
\hline \multicolumn{9}{|l|}{ Etiology } \\
\hline Idiopathic & 139 & 45 & 30 & 40 & 8 & 67 & 177 & 44.3 \\
\hline Arteriosclerotic & 86 & 28 & 32 & 43 & 3 & 25 & 121 & 30.3 \\
\hline Rheumatic & 32 & 10 & 5 & 7 & - & - & 37 & 9.2 \\
\hline Cardiomyopathy & 14 & 4 & 6 & 8 & - & - & 20 & 5.0 \\
\hline Aortic Valve Disease & 31 & 10 & 2 & 3 & 1 & 8 & 34 & 8.5 \\
\hline Congenital & 8 & 3 & - & - & - & - & 8 & 2.0 \\
\hline Other & 2 & 1 & - & - & - & - & 2 & .5 \\
\hline
\end{tabular}

* \% expressed as a percent in each diagnostic category.

$* \%$ expressed as a percent in entire series.

sinoatrial arrest in combination with supraventricular arrhythmias-the "bradycardia-tachycardia syndrome."

\section{Survival}

The current status of the patient population is outlined in Table III. Only $1 \%$ of the patients were lost to follow-up. Forty-eight percent died. Death was most commonly due to underlying cardiac disease as manifested by sudden death in 41 (21\% of all deaths), congestive heart failure $(15 \%$ of deaths), myocardial infarction $(9 \%)$, and arrhythmias (5\%). Sudden death was the single most common cause of death in the AV block group, while congestive heart failure was most common in the sinus node group (Table III). Stroke and malignancy were the major causes of noncardiac death. Six deaths were attributed to complications of a thoracotomy-all of these occurred prior to 1965 when all implants were performed by this technique. Two deaths occurred within one week of a transvenous implant and were attributed to acute myocardial infarction. Twenty-one of the 22 patients whose cause of death was unknown died prior to 1972 when the cause of death was not ascertained within six weeks of death. Pacemaker failure was the documented cause of death in only three patients, but was suspected in several additional cases. Two patients, known to be pacemaker dependent, died suddenly within one month of a new transvenous lead implantation, and one patient who died suddenly was being paced with a pulse generator from series known to have a "no-output" failure mode.

Actuarial survival was virtually identical in the two major bradyarrhythmia categories. Survival in the AV block group was 88, 79, 60 and $49 \%$, at one, two, five and 10 years, respectively (Fig. 2), while the sinus node group had an 85,79 , and $65 \%$ survival at one, two, and five years $(p=$ N.S.) (Fig. 3). The sinus bradycardia subgroup of patients with sinus node disease had a slightly 
Table II.

Major Associated IIInesses prior to Initial Pacemaker Implantation Correlated with Indication for Pacing in the Study Population

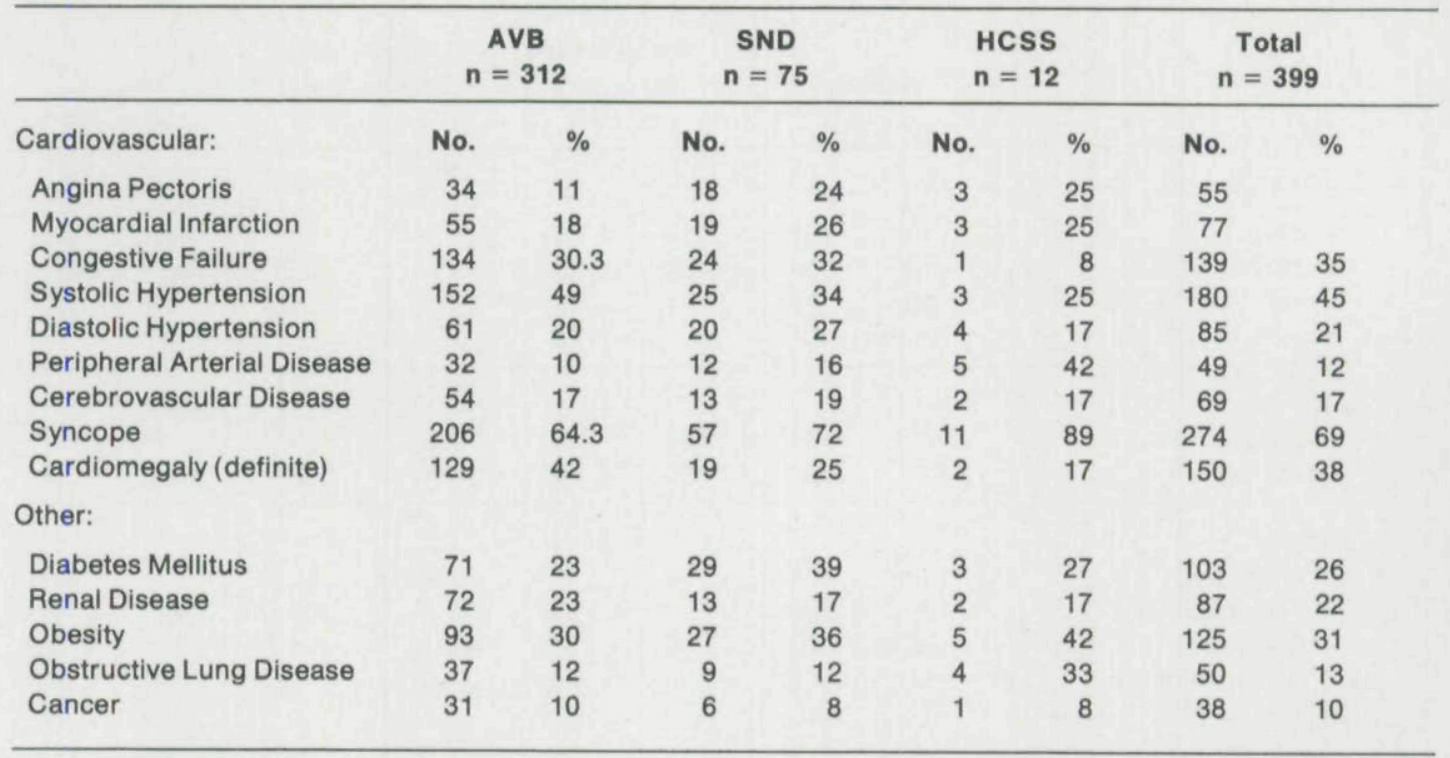

$\mathrm{AVB}=$ atrioventricular block; SND = sinus node disease; HCSS = hypersensitive carotid sinus syndrome.

Table III.

Current Status of the Population and Reasons for Death

\begin{tabular}{|c|c|c|c|c|c|c|c|c|}
\hline \multirow[b]{2}{*}{ Current Status } & \multirow{2}{*}{$\begin{array}{c}\text { AV Block } \\
n=312 \\
\text { No. }\end{array}$} & \multirow[b]{2}{*}{$\%$} & \multicolumn{2}{|c|}{$\begin{array}{c}\text { Sinus } \\
\text { Node Disease } \\
n=75\end{array}$} & \multicolumn{2}{|c|}{$\begin{array}{c}\text { Hypertensive } \\
\text { Carotid } \\
\text { Sinus Syndrome } \\
n=12\end{array}$} & \multicolumn{2}{|c|}{$\begin{array}{c}\text { Total } \\
n=399\end{array}$} \\
\hline & & & No. & $\%$ & No. & $\%$ & No. & $\%$ \\
\hline Alive and paced & 144 & 46 & 43 & 57 & 8 & 67 & 195 & $49^{*}$ \\
\hline Alive, unpaced & 3 & 1 & 3 & 4 & 2 & 17 & 8 & $2^{*}$ \\
\hline Lost to follow-up & 3 & 1 & 1 & 1 & - & - & 4 & $1^{*}$ \\
\hline Dead & 162 & 52 & 29 & 37 & 2 & 17 & 193 & $48^{*}$ \\
\hline \multicolumn{9}{|l|}{ Cause of Death } \\
\hline Cardiac: & 75 & 48 & 18 & 64 & - & - & 93 & $48^{* *}$ \\
\hline Sudden Death & 41 & 25 & - & - & - & - & 41 & 21 \\
\hline $\mathrm{CHF}$ & 20 & 13 & 8 & 39 & - & - & 28 & 15 \\
\hline $\mathrm{MI}$ & 11 & 7 & 7 & 25 & - & - & 18 & 9 \\
\hline Arrhythmia & 3 & 2 & 3 & 11 & - & - & 6 & 5 \\
\hline Non-Cardiac: & 57 & 36 & 7 & 25 & 2 & 100 & 66 & $34^{* *}$ \\
\hline CNS & 20 & 13 & - & - & - & - & - & - \\
\hline Cancer & 17 & 11 & - & - & 1 & 50 & - & - \\
\hline Other & 20 & 13 & 7 & 25 & 1 & 50 & 25 & 13 \\
\hline Unknown & 22 & 14 & 3 & 11 & - & - & 25 & $12^{* *}$ \\
\hline Pacemaker Failure & 3 & 2 & - & - & - & - & 3 & $2^{* *}$ \\
\hline Perioperative & 6 & 4 & - & - & - & - & 6 & $3^{* *}$ \\
\hline
\end{tabular}

* Expressed as a percent of all patients.

** Expressed as a percent of all deaths. 
better long-term prognosis $(72 \%$ survival at five years) than those with sinoatrial arrest or bradytachy syndrome $(67 \%$ and $64 \%$ five-year survival, respectively) but the difference was not statistically significant. The preimplant variables which were associated with a poor survival included advanced age, especially in the AV block group (Fig. 2), the presence of congestive heart failure, especially in the sinus node group (Figs. 4, 5), and most importantly, the presence of ischemic or hypertensive heart disease in both groups (Figs. 6 and 7).

Patients with AV block and sinus node disease associated with ischemic heart disease have been shown to have poor survival. ${ }^{9,10}$ The high-risk group also includes those with apparent primary myocardial disease (Fig. 6). Those patients with valvular heart disease, either on a rheumatic basis or with isolated aor- tic valve disease, and patients with only idiopathic conduction system disease did distinctively better. Although there was a trend toward poorer survival in those treated early in the pacing era, possibly due to a higher perioperative mortality with epicardial electrodes, this was not statistically significant $(p<.3)$. The subgroup with hypersensitive carotid sinus syndrome had no deaths until the eighth year, possibly because of the low prevalence of ischemic heart disease and the younger age.

\section{Late Morbid Events in the Population Studied}

Myocardial infarction, major central nervous system events (stroke, transient ischemic events, organic brain syndrome, and overt psychiatric depression even leading to suicidal attempts, ${ }^{18}$ as well as worsening renal function and major

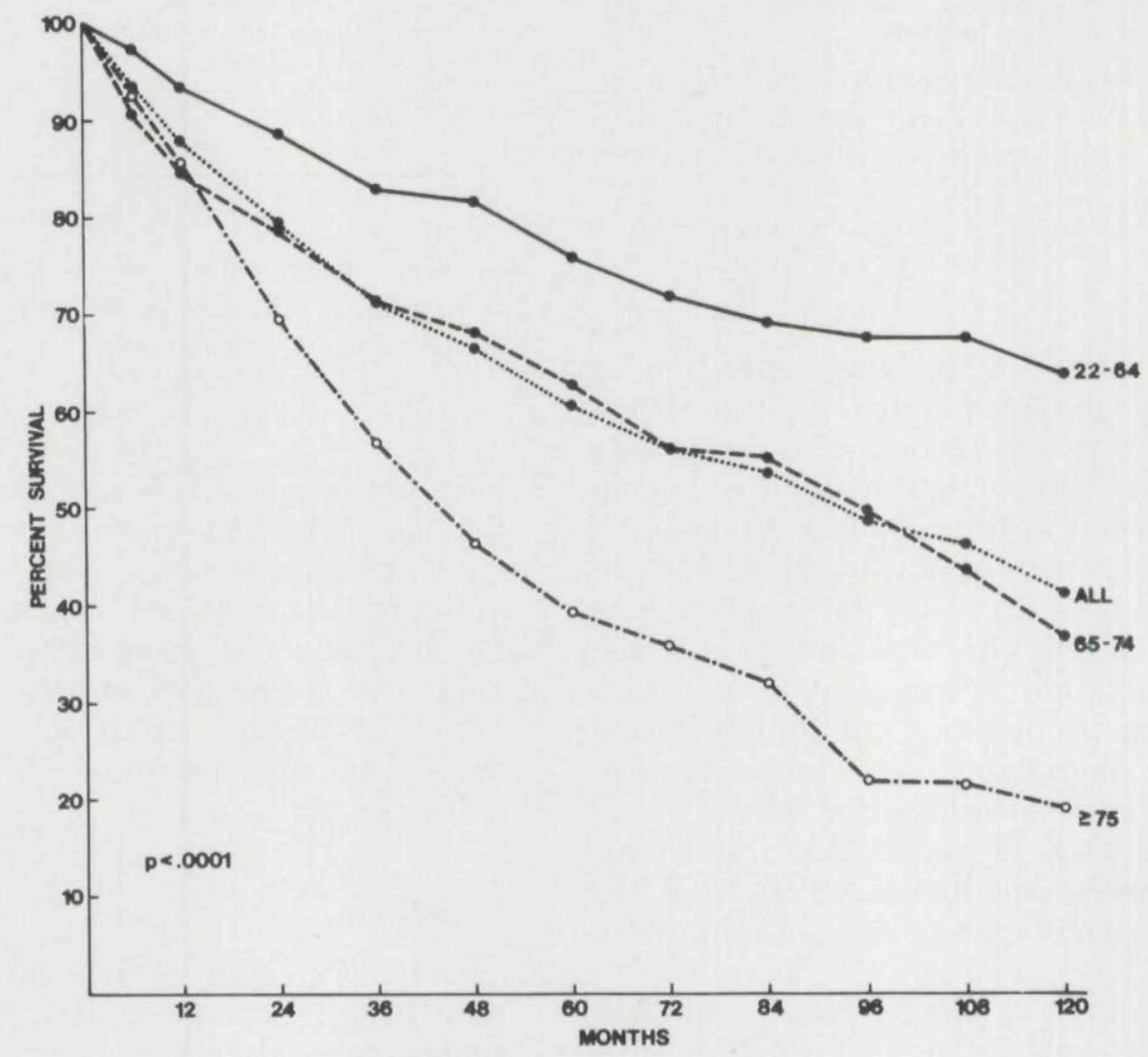

Figure 2. Actuarial survival in the AV block group is highly correlated with age at initial implant. Less than $50 \%$ over age seventy-five survived 48 months. 


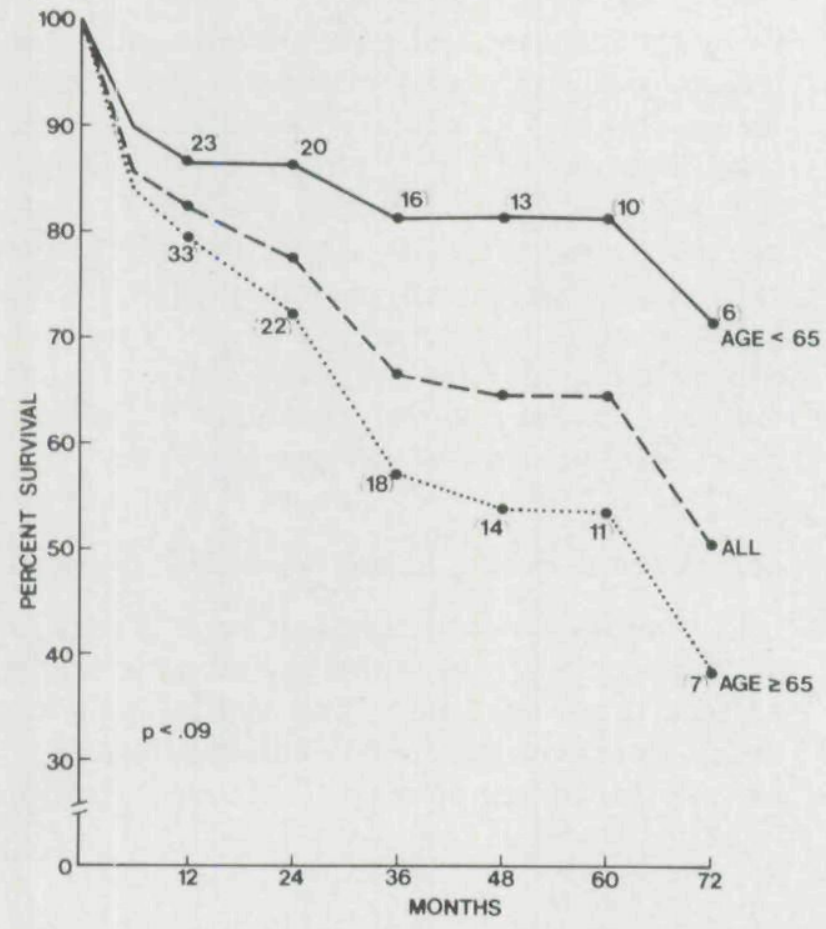

Figure 3. Actuarial survival of age in the sinus node disease subgroup-although not statistically significant, a distinct trend toward poorer survival with advanced age is noted.

pulmonary complications) were noted during the follow-up period (Table IV). Congestive heart failure was the single most common late morbid event in this group. During the follow-up period, $33(10.6 \%)$ of the AV block group and 5 $(7 \%)$ of the sinus node group developed CHF. In only 18 of the 134 with CHF prior to pacemaker implantation did all clinical evidence of it disappear to the point where digitalis and diuretics could be discontinued indefinitely during follow-up. In six patients these drugs were discontinued for an extended period only to be required again later. De novo CHF, which required treatment, was diagnosed in 33 of 166 (21\%) of the AV block group free of CHF prior to implant.

While 86 patients in the AV block group had had a valvular component to their heart disease, the valve disease was felt to be incidental in 20 (e.g., papillary muscle dysfunction secondary to ischemic heart disease, etc). Fifty-two

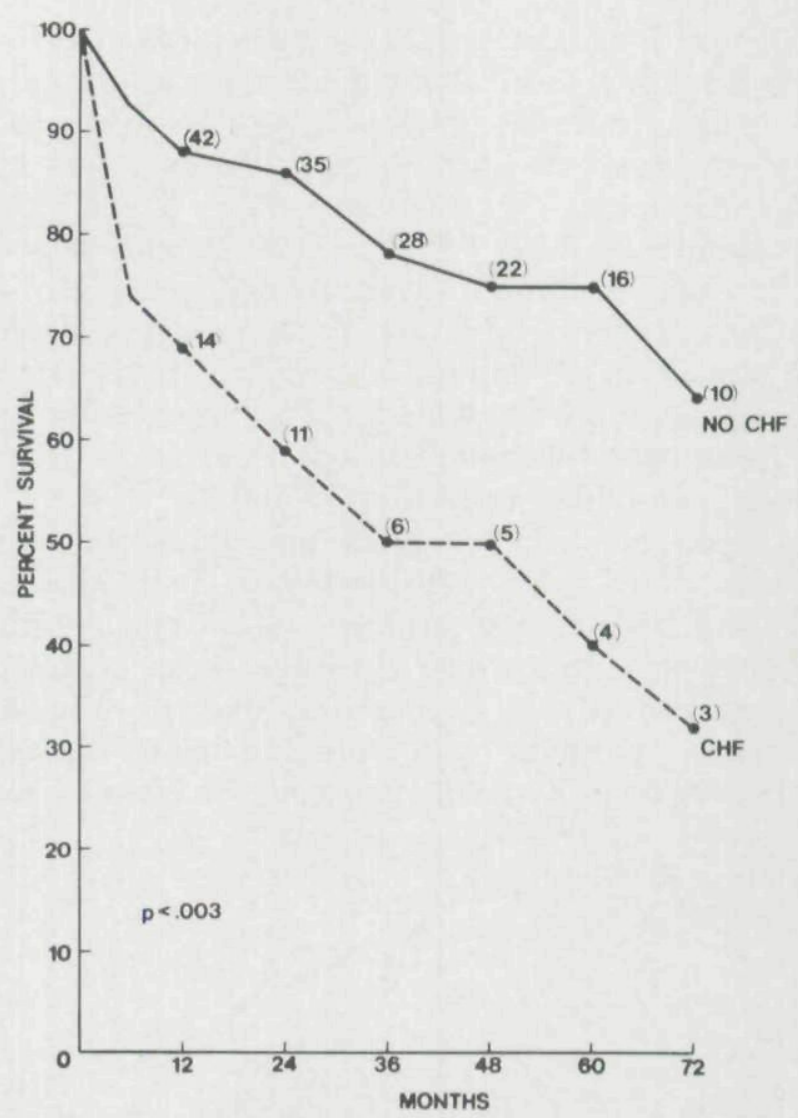

Figure 4. Actuarial survival in the sinus node group as correlated with the presence of congestive heart failure prior to implant.

have not required valve replacement; in three, the pacemaker implantation preceded eventual valve replacement; in nine, pacemaker and valve replacement occurred during the same hospitalization ( 5 because of iatrogenic AV block and in 4 because of preoperative arrhythmias); in 12 patients valve replacement had been accomplished prior to eventual pacemaker implantation.

\section{Discussion}

The poor overall survivorship with both sinus node disorders and AV block is consistent with reports from elsewhere ${ }^{19-23}$ and extends for another four years the observations made from this institution reported previously. ${ }^{9,10}$ Patients paced for hypersensitive carotid sinus syn- 


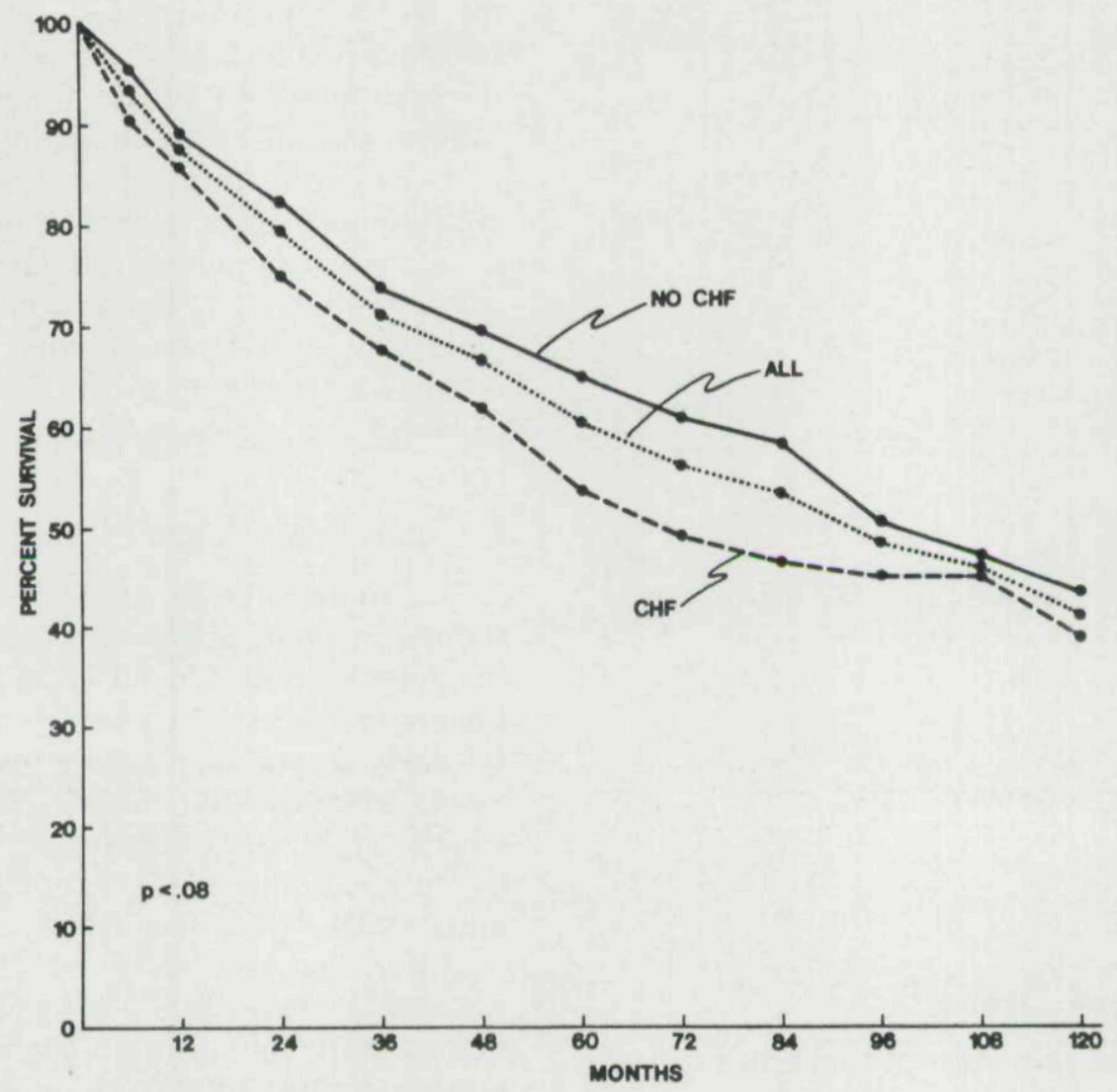

Figure 5. A trend is seen in the AV block group between late survival and the presence of congestive heart failure prior to implant.

drome appear to do better-probably because of younger age and lower prevalence of ischemic heart disease, and congestive heart failure. In fact, no deaths occurred for the first eight years of follow-up in this latter group of paced patients.

The patient population with symptomatic bradyarrhythmias which require permanent pacemaker placement is generally an elderly one with a high prevalence of cardiac and noncardiac physical ailments. The correlation between age at initial implant and poor survival has been reported in multiple previous studies, as well as from this series. Patients with pacemakers, in addition, have a higher than expected age-specific mortality than the population at large. ${ }^{20,21}$ Poor survival was also highly correlated with left ventricular dysfunction prior to implantation and an ischemic or hyper- tensive etiology of the underlying heart disease ${ }^{20,22,24}$ The poor survival in the presence of congestive heart failure for patients with AV block or sinus node disease was apparent in earlier reports from this series; an even poorer survival has been reported in other series. Laczkovics, ${ }^{24}$ for example, has reported a $50 \%$ mortality at 36 months in patients paced for CHF; Castberg $^{23}$ reported a $50 \%$ mortality in a similar group of patients at 48 months. More physiologic pacing modes (e.g., atrioventricular sequential, DVI) have been demonstrated to improve cardiac output in selected patients when compared to ventricular pacing and might, therefore, be expected to improve survivorship for those patients who succumb to the complications of CHF, but clinical evidence for this has not been presented.

The high mortality, despite pacing, in the 


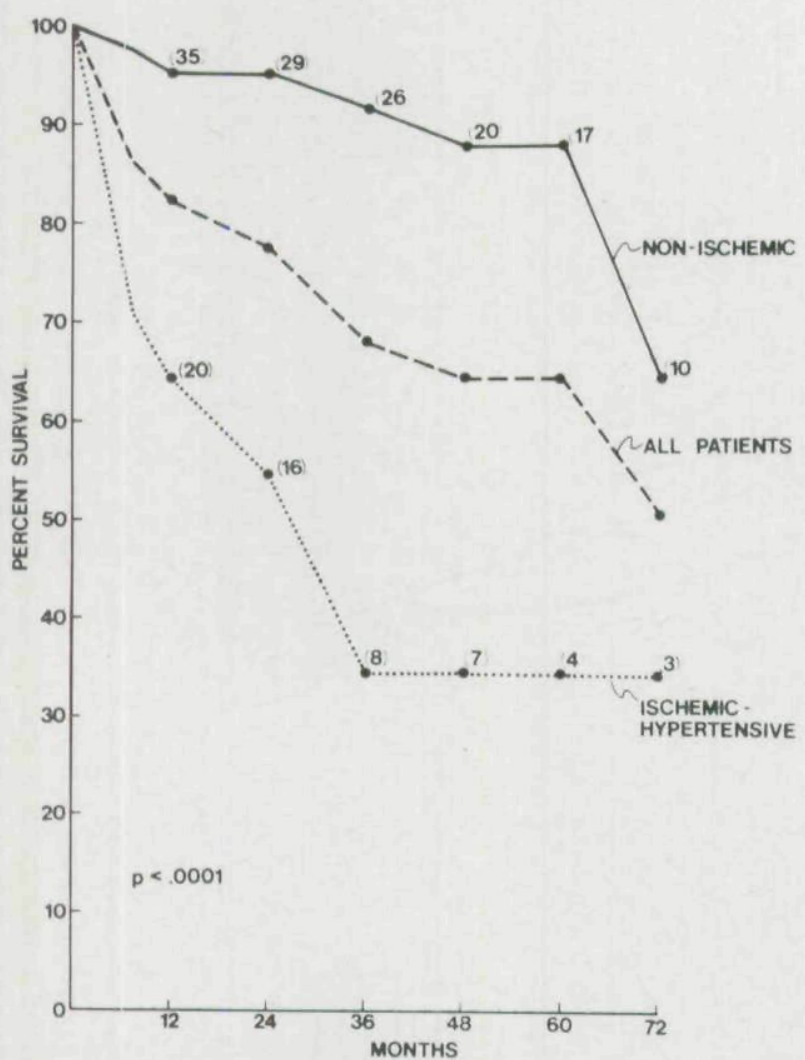

Figure 6. Actuarial survival in the sinus node group was highly correlated with the etiology of underlying heart disease. Only one third of those with ischemic or hypertensive heart disease survived over 36 months.

sinus node subgroup, especially in those patients with coexistent ischemic heart disease or congestive heart failure, deserves special emphasis-only $33 \%$ surviving over 36 months. There is growing evidence that, unlike patients paced for AV block, prolongation of life has not been demonstrated in patients with sinus node disease when compared to a non-paced population. ${ }^{28}$ Other potentially reversible causes of cardiac mortality (e.g., major ventricular arrhythmias, myocardial ischemia, etc.) should be searched for and treated if survivorship is to be improved in this subgroup. Pacing appears mainly to bring symptomatic relief from syncope in such patients.

The distribution of causes of late death are consistent with studies reported elsewhere. ${ }^{24-26}$ Complications of underlying heart disease were the major cause of death in all reported series. In this series sudden death was more common in the group with AV block, while congestive heart failure was the more common mode of death in patients with sinus node disease. Pacemaker malfunctions as a demonstrated cause of late death is uncommon in all series in which this was mentioned. ${ }^{9,10,20,26}$ Determination of pacing system integrity immediately prior to or after death was made in only a few who died suddenly in this series, however.

\section{Potential Implications of Improved Technology}

Improvements in patient follow-up techniques and pacing system programmability may improve patient prognosis in the future. Telephone monitoring, currently used extensively for early detection of battery depletion, can also detect asymptomatic pacing system malfunction which might otherwise lead to early mortality, as well as detect potentially malignant arrhythmias amenable to treatment.

Multiprogrammability, especially output adjustability, appears to be most useful in reducing early operative intervention to correct system malfunction. ${ }^{27}$ It may, however, also reduce the risk of early acute threshold elevation in pacemaker-dependent individuals. Sensitivity adjustability may prevent fatal arrhythmias which can occasionally result from poor sensing of competing rhythms.

Heart failure that accompanies AV block or other bradyarrhythmias is partially due to the bradyarrhythmia itself and to impaired left ventricular function and persistent cardiomegaly. Continued reliance on digitalis and diuretics for continued hemodynamic stability after pacing is generally required. ${ }^{10}$ Whether the maintenance of atrioventricular synchrony with more physiologic pacing systems will not only improve cardiac output, as has been demonstrated in acute studies, but also actually prevent death due to progressive ventricular dysfunction and prolong survival remains to be determined. In addition to advances in pacemaker technology, other improvements in the management of patients with clinically important bradyarrhythmias will continue, as they have throughout this clinical series. The early application of coro- 


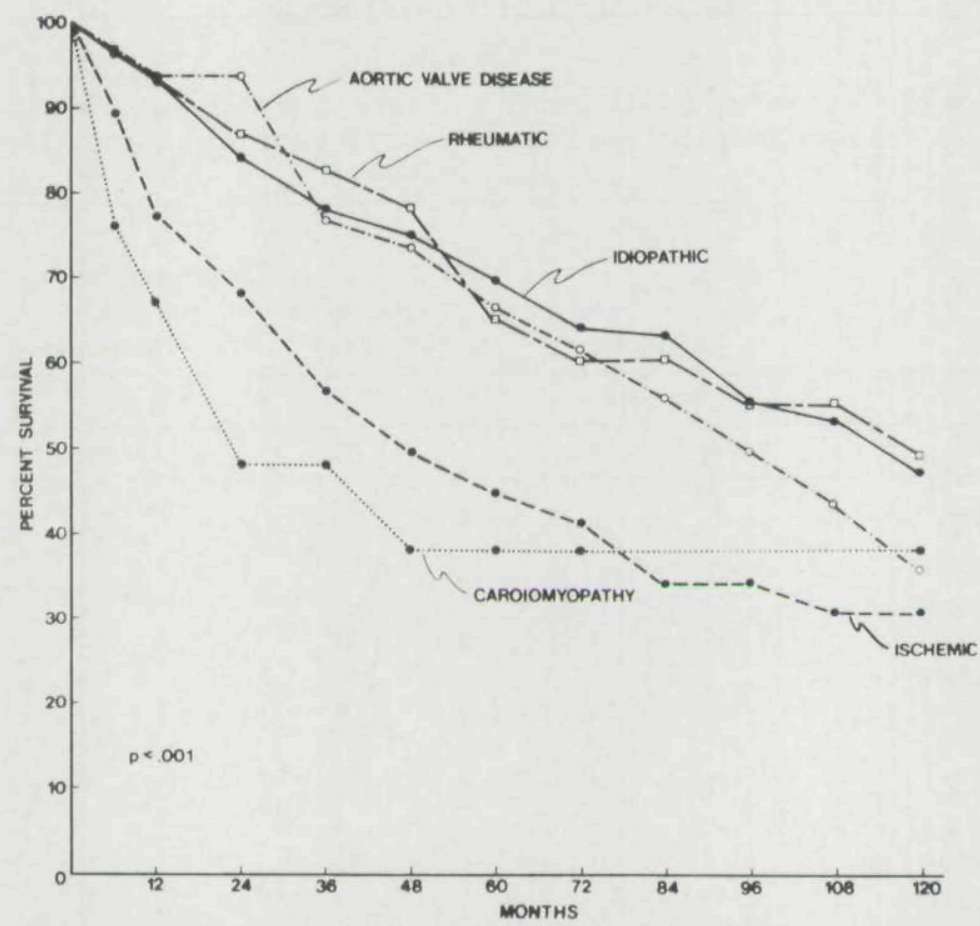

Figure 7. Correlation between survival and clinically determined etiology of underlying heart disease within the AV block group. Patients with ischemic/hypertensive heart disease and primary myocardial disease clearly fared poorest.

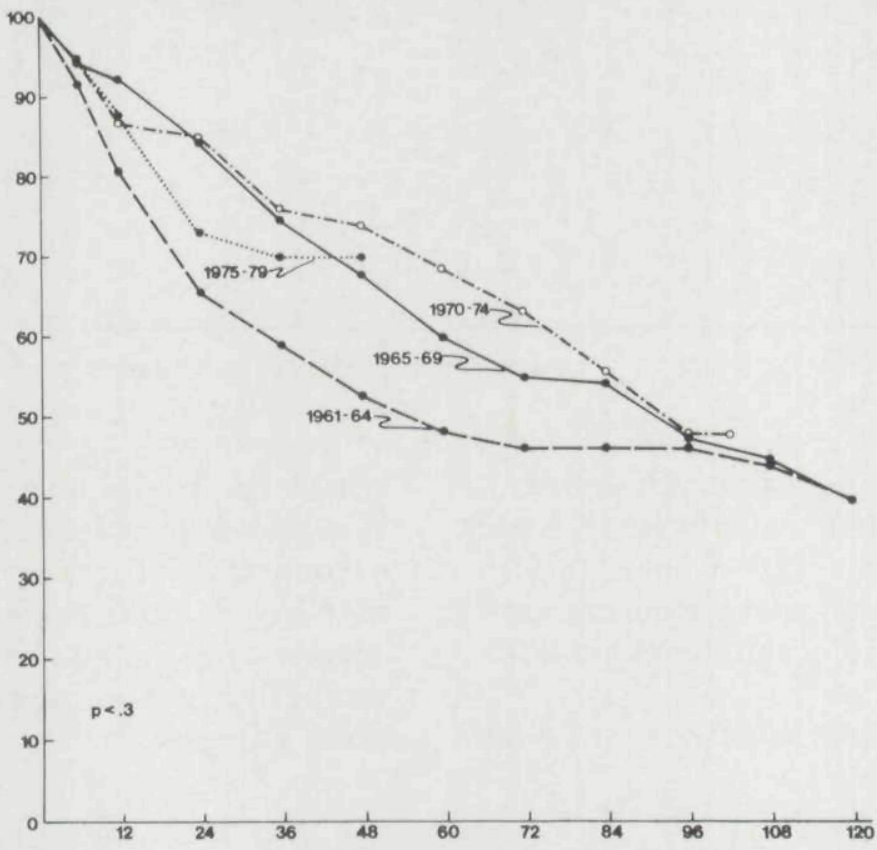

Figure 8. Despite improvements in the overall management of patients with heart disease and an apparent lower implantation complication rate in the later time periods, there was no significant difference in survivorship between those paced early in pacing experience, and those paced more recently. 
Table IV.

The Prevalence of Major Morbid Events During the Follow-up Interval as Correlated with the Specific Bradyarrhythmia. The AV Block Group Has Been Followed for Eight Years Longer Than Those with Sinus Node Disease

\begin{tabular}{|c|c|c|c|c|c|c|c|c|}
\hline & \multicolumn{2}{|c|}{ AV Block } & \multicolumn{4}{|c|}{$\begin{array}{l}\text { Hypersensitive } \\
\text { Carotid } \\
\text { Sinus Syndrome }\end{array}$} & \multicolumn{2}{|c|}{ Total } \\
\hline & \multicolumn{2}{|c|}{$\mathbf{n}=312$} & \multicolumn{2}{|c|}{$n=75$} & \multicolumn{2}{|c|}{$n=12$} & \multicolumn{2}{|c|}{$n=399$} \\
\hline & $\mathbf{n}$ & $\%$ & $\mathbf{n}$ & $\%$ & $\mathbf{n}$ & $\%$ & $\mathbf{n}$ & $\%$ \\
\hline Myocardial Infarction & 27 & 8.0 & 8 & 10 & 3 & 25 & 38 & 10 \\
\hline $\begin{array}{l}\text { CNS Events } \\
\text { Transient Ischemic }\end{array}$ & & & & & & & & \\
\hline $\begin{array}{l}\text { Events } \\
\text { Stroke (traumatic }\end{array}$ & 13 & 4 & 3 & 4 & - & - & 16 & 4 \\
\hline $\begin{array}{l}\text { or embolic) } \\
\text { Organic brain }\end{array}$ & 34 & 11 & 3 & 4 & - & - & 37 & 9 \\
\hline $\begin{array}{l}\text { syndrome } \\
\text { Significant }\end{array}$ & 12 & 4 & 2 & 1 & - & - & 14 & 4 \\
\hline depression & 3 & 1 & 2 & 1 & - & - & 4 & 1 \\
\hline Congestive Heart & & & & & & & & \\
\hline Failure & 33 & $21^{* *}$ & 5 & $12^{* *}$ & 2 & $18^{* *}$ & 40 & $15^{* *}$ \\
\hline Pulmonary Disease & & & & & & & & \\
\hline $\begin{array}{l}\text { Pneumonia } \\
\text { Progressive COPD }\end{array}$ & $\begin{array}{r}19 \\
9\end{array}$ & $\begin{array}{l}6 \\
3.5\end{array}$ & $\begin{array}{l}5 \\
1\end{array}$ & $\begin{array}{l}6 \\
1\end{array}$ & $\overline{1}$ & $\overline{-}$ & $\begin{array}{l}24 \\
10\end{array}$ & $\begin{array}{l}6 \\
3\end{array}$ \\
\hline Diabetes (new onset) & 6 & 2 & - & - & 3 & 25 & 9 & 5 \\
\hline Renal Disease & & & & & & & & \\
\hline $\begin{array}{l}\text { New or worsening } \\
\text { azotemia } \\
\text { New obstructive }\end{array}$ & 21 & 8 & 3 & 4 & - & - & 24 & $8^{* *}$ \\
\hline uropathy & 13 & $6^{*}$ & - & - & 1 & - & $14^{*}$ & $6^{*}$ \\
\hline Cancer & 18 & 6 & 1 & 1 & - & - & 19 & 5 \\
\hline
\end{tabular}

* Expressed as a percent of males.

** Expressed as percent of those free of condition prior to implant.

nary revascularization and valve replacement, as well as more effective pharmacologic methods of control of congestive heart failure and tachyarrhythmias, will make measurement of the effect of any one intervention mode difficult.

Because of the multiple apparent variables which contribute to morbidity and mortality in the paced population, it will be difficult to demonstrate that multiparameter programmability or dual chamber pacing will prolong survivorship despite evidence that it can reduce morbidity and enhance the quality of life of these patients.

\section{References}

1. Judge, R.D., Wilson, W.S., and Siegel, J.H.: Hemodynamic studies on patients with implanted cardiac pacemakers. N. Engl. J. Med., 270:1391, 1964.

2. Preston, T.A., and Judge, R.D.: High myocardial threshold to an artificial pacemaker. Report of a fatal case. N. Engl. J. Med., 276:798, 1967.

3. Preston, T.A., Judge, R.D., Bowers, D.L., et al.: 
Measurement of pacemaker performance. Am. Heart J., 71:92, 1966.

4. Preston, T.A., Judge, R.D., Lucchesi, B.R., et al.: Myocardial threshold in patients with artificial pacemakers. Am. J. Cardiol., 18:83, 1966.

5. Morris, J.D., and Judge, R.D.: Myocardial electrode implantations: indications and advantages. Ann. N.Y. Acad. Sci., 167:987, 1969.

6. Judge, R.D., Preston, T.A., Leininger, B.J., et al.: Clinical experience and problems encountered with implantable pacemaker. J. Thorac. Cardiovasc. Surg. 50:849, 1965.

7. Kahn, D.R., Kirsh, M.M., Vathayanon, S., et al.: Long term evaluation of the General Electric cardiac pacemaker. Thorax, 25:267, 1970.

8. Davidson, D.M., Braak, C.A., Preston, T.A., et al.: Permanent ventricular pacing: effect on long term survival, congestive heart failure, and subsequent myocardial infarction and stroke. Ann. Intern. Med., 77:345, 1972.

9. Simon, A.B., and Zloto, A.E.: Atrioventricular block: Natural history after permanent ventricular pacing. Am. J. Cardiol., 4:500, 1978.

10. Simon, A.B., and Zloto, A.E.: Symptomatic sinus node disease: Natural history after permanent ventricular pacing. PACE, 2:305, 1979.

11. Fox, D.J., and Guire, K.E.: Documentation for MIDAS (Michigan Interactive Data Analysis System), second edition (revised), 1974. Statistical Research Laboratory, University of Michigan, Ann Arbor, Michigan.

12. Heilbrun, L.K.: Documentation of IGSAS (Interactive Graphics Survival Analysis System), second edition, 1975, Dept. of Biostatistics, School of Public Health, University of Michigan, Ann Arbor, Michigan.

13. Gehan, E.A.: Estimating survival functions from the life table. J. Chron. Dis., 21:629, 1969.

14. Cutler, S.J., and Ederer, F.: Maximum utilization of the Life Table Method in analyzing survival. J. Chron. Dis., 8:699, 1958.

15. Breslow, N.: A generalized Kruskal-Wallis Test for comparing $\mathrm{K}$ samples subject to unequal pat- terns of censorship. Biometrika, 57:579, 1970.

16. McKee, P.A., Castelli, W.P., McNamara, P.M., et al.: The natural history of congestive heart failure: The Framingham Study. N. Engl. J. Med., 285:1441, 1971.

17. Simon, A.B., Dick, M., Stern, A., et al.: Permanent cardiac pacing in children. (Submitted for publication.)

18. Simon, A.B., Kleinman, P., Janz, N.: Suicide attempt by pacing system abuse. PACE, 3:224, 1980.

19. Furman, S., and Whitman, R.: Cardiac pacing and pacemakers. Statistical analysis of pacemaker data. Am. Heart J., 95:115, 1978.

20. Fitzgerald, W., Graham, I.M., Cole, T., et al.: Age, sex, and ischemic heart disease as prognostic indicators in long term cardiac pacing. Br. Heart J., 42:57, 1979.

21. Ginks, W., Leatham, A. and Siddons, H.: Prognosis of patients paced for chronic atrioventricular block. Br. Heart J., 41:633, 1979.

22. Hashiba, K.: Indication and long term results of artificial pacemakers. Jpn. J. Med., 17:373, 1978.

23. Castberg, T.: Patient survival during pacemaker treatment. Scand. J. Thorac. Cardiovasc. Surg,, Suppl 22:57, 1978.

24. Laczkovics, A., Mohl, W., and Steinbach, K.: Life expectancy of patients in relation to age and indications for pacemaker treatment. In, C. Meere (Ed.): Proceedings of the 6th World Symposium on Cardiac Pacing. Montreal, Pacesymp, 1979, p. 13-14.

25. Siddons, H.: Deaths in long term paced patients. Br. Heart J., 36:1201, 1974.

26. Codini, M.A., Caralis, D.G., and Voight, G.C.: Permanent ventricular pacing. A Ten Year Experience. Johns Hopkins Med. J., 134:118, 1974.

27. Furman, S.: Operative revision reduction with output programmable pulse generators. Am. J. Cardiol., 47:393, 1981.

28. Shaw, D.B., Holman, R.R., and Gowers, J.I.: Survival in sinoatrial disorders. Br. Med. J., 1:139, 1980. 
This document is a scanned copy of a printed document. No warranty is given about the accuracy of the copy. Users should refer to the original published version of the material. 